\title{
MONITORAMENTO QUANTITATIVO DE MATERIAL PARTICULADO NA REGIÃO CENTRAL DE GOIÂNIA - GO
}

Adivania Cardoso da Silva - adivania.cardoso@hotmail.com Instituto Federal de Educação, Ciência e Tecnologia de Goiás - IFG

Nadine de Paula Santos - nadinedepaula54@ hotmail.com Instituto Federal de Educação, Ciência e Tecnologia de Goiás - IFG Bruno dos Santos Ferreira Roque - brunoroque07@ gmail.com Instituto Federal de Educação, Ciência e Tecnologia de Goiás - IFG

Ana Carla Fernandes Gomes - anacarlaifg@ hotmail.com Instituto Federal de Educação, Ciência e Tecnologia de Goiás - IFG 


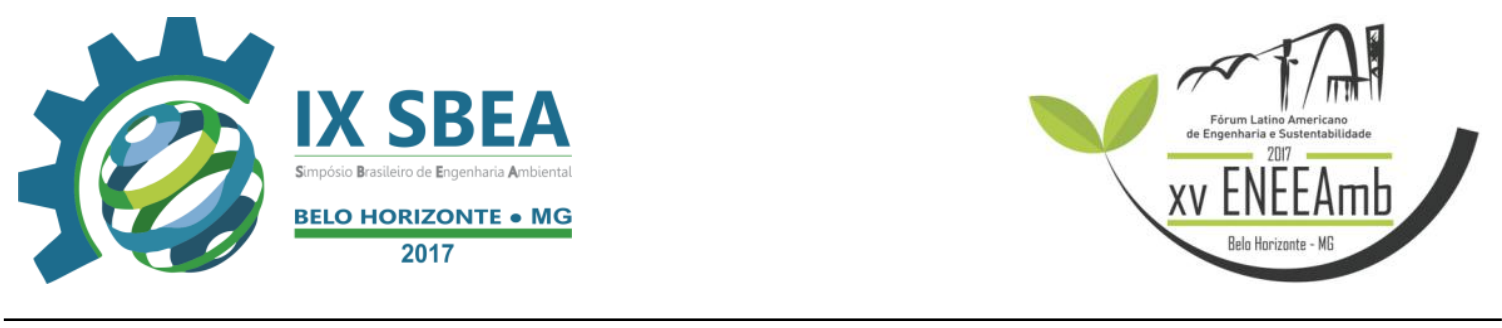

\section{RESUMO}

Material particulado são partículas no estado sólido ou líquido com diâmetro aerodinâmico menor que 100 micrômetros, que tem sido considerado um poluente atmosférico associado a problemas respiratórios, devido a sua capacidade de penetração no organismo e atingir os alvéolos pulmonares. A proposta deste trabalho foi monitorar concentrações de material particulado (MP) na região central de Goiânia - GO, utilizando um amostrador de particulado fino e grosso (AFG) por meio da filtragem sequencial do ar atmosférico e da coleta do material particulado por impactação inercial em duas frações separadas. Através desse monitoramento quantificou-se concentrações de material particulado fino e grosso, MP2,5 e MP10, respectivamente, em microgramas por metros cúbicos, na Praça do Trabalhador em Goiânia. Os valores do material particulado quantificado na região central da cidade de Goiânia - GO, no período de dezembro de 2015, apresentando média de concentração de $11,4946 \mu \mathrm{g} \cdot \mathrm{m}^{-3}$ e 8,9121 $\mu \mathrm{g} . \mathrm{m}^{-3}$ com desvio médio de 6,8983 e 4,6625 para MP2,5 e MP10, respectivamente, com pico acentuado de concentração para o MP2,5 fora do permitido segundo a Organização Mundial de Saúde. Considerando que a melhoria da qualidade de vida das pessoas depende de um meio ambiente saudável logo é preciso monitorar, dentre outros aspectos, a qualidade do ar a fim de verificar se suas condições garantem o direito à saúde, e como forma de perpetuar esse direito constitucional, faz-se necessário à adoção de medidas mitigadoras, eliminadoras ou compensatórias a esse meio, através da proposição de parâmetros legais, políticas e ações de prevenção, até então não estabelecidos.

Palavras-chave: Monitoramento, atmosfera, medidas mitigadoras, material particulado.

\section{INTRODUÇÃO/OBJETIVO}

A poluição do ar existe quando neste estão presentes substâncias químicas (poluentes atmosféricos) que em concentrações suficientes podem causar danos à saúde dos serres vivos ou aos bens materiais. As substâncias classificadas como materiais particulados não possuem uma característica específica, pois estas podem ser qualquer partícula sólida ou líquida presente na atmosfera. Essas partículas são classificadas de acordo com seu diâmetro aerodinâmico, sendo que as partículas com diâmetro menor do 


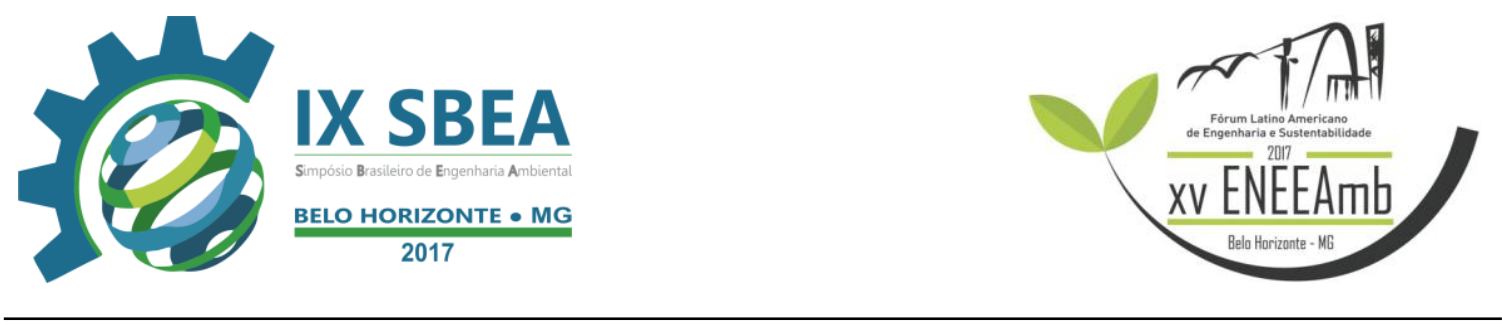

que 2,5 micrômetros $(\mu \mathrm{m})$ são consideradas finas (MP2,5) e as que permanecerem entre 2,5 $\mu \mathrm{m}$ e $10 \mu \mathrm{m}$ são consideradas grossas (MP10) (ROCHA et al., 2009).

Atualmente Goiânia é classificada como uma metrópole regional e consolidou a base de sua economia no setor de serviços, mas também tem apresentado ultimamente um grande desenvolvimento industrial. Com esse potencial de crescimento e uma boa qualidade de vida, a metrópole regional tem atraído migrantes e novas empresas, o que significa um crescimento populacional e um maior desenvolvimento econômico (COSTA E SILVA, 2015). Houve também nós últimos anos um grande aumento da frota de veículos, o que também está totalmente relacionado com esse desenvolvimento (PASQUALETTO, 2009). Porém, esse crescimento urbano não ocorre sem consequências, pois influencia diretamente na condição atmosférica (COSTA E SILVA, 2015). As emissões atmosféricas produzem vários efeitos adversos sobre o ambiente e a população e sua saúde.

Além das mais diversas ações antrópicas, a cidade de Goiânia está localizada na região onde ocorrem diversas queimadas, principalmente durante a época de estiagem, época do ano na qual a umidade do ar diminui e a qualidade do ar se torna precária, trazendo transtornos à população (PASQUALETTO, 2009).

Apesar de todo o crescimento da região, os problemas ambientais, como a poluição e degradação da atmosfera, aumentaram e continuam aumentando cada vez mais (IBGE; DENATRAN, 2013).

Portanto, sendo o material particulado considerado um poluente atmosférico que pode causar danos à saúde humana (WHO, 2006) e na de outros animais é de grande importância estudar e monitorar as concentrações em microgramas por metros cúbicos desse tipo de poluente, sendo ele que pode afetar o clima tanto em escala regional como em escala global (COLLS, 2002), que também pode ter efeitos nocivos dependendo do grau de exposição, de concentração dos poluentes, da idade do indivíduo e da condição de saúde (CALIJURI \& CUNHA, 2013; BRIGGS et al., 1996 apud PHILIPPI JÚNIOR, 2005).

Além dos prejuízos à saúde da população, o material particulado possui tempo de residência na atmosfera que podem variar de dias a semanas. Esse material pode ser transportado a longas distâncias por correntes de ar, podendo interferir nas 
características físico-químicas da atmosfera e ainda podendo causar potencial incômodo por sua deposição em materiais e edificações (CASTANHO, 1999).

Segundo Seinfeld e Pandis (2006), o material particulado na atmosfera é produzido por diversas fontes de emissão e consiste em um conjunto de partículas de tamanhos variados, apresentando diferentes graus de toxicidade. E ainda Segundo a Companhia Ambiental do Estado de São Paulo - CETESB (2008), essas partículas, quando inaladas depositam-se em diferentes regiões do trato respiratório, podendo se alojar nos bronquíolos, ou até mesmo se depositar no tecido pulmonar.

As profundidades que uma partícula pode alcançar estão associadas ao seu diâmetro aerodinâmico, ou seja, partículas menores poderão alcançar profundidades maiores. E isso ocorre porque os mecanismos de defesa do organismo humano são adequados para remover diversas partículas inaladas maiores que $10 \mu \mathrm{m}$, as partículas menores que têm 2,5 $\mu$ m de diâmetro $(\mathrm{MP} 2,5)$ causam sérios danos à saúde (GODISH, 1997). Por isso, essas partículas ultrafinas que representam o material particulado fino estão recentemente atraindo atenção de cientistas tendo em vista as evidências dos efeitos toxicológicos destas partículas na saúde humana (WHO, 2006).

Segundo estudos ecológicos de séries temporais, desenvolvidos em Cuiabá-MT e Piracicaba-SP, que analisaram a associação entre material particulado fino, originado da queima de biomassa, e as internações por doenças respiratórias em crianças e idosos, ficou constatado, em ambos os casos, a influência do material particulado fino (MP2,5) sobres as internações hospitalares por doenças respiratórias (SILVA et al., 2013; CESAR et al., 2013).

E apesar da maioria das doenças causadas pelo material particulado serem de origem respiratória, atualmente a poluição atmosférica também tem um peso significativo nas mortes prematuras. Segundo a Organização Mundial de Saúde (WHO, 2006) mais de 2 milhões de pessoas morrem anualmente devido aos efeitos da poluição do ar. E também segundo um estudo feito em Santo André - SP por Romão (2010) demonstrou a relação existente entre a exposição a material particulado grosso e o nascimento de bebês com baixo peso. Esse estudo confirma que os efeitos adversos causados pelo MP não estão restritos às complicações respiratórias e cardiovasculares, mas, possuem também, implicações significativas no resultado da gestação. 


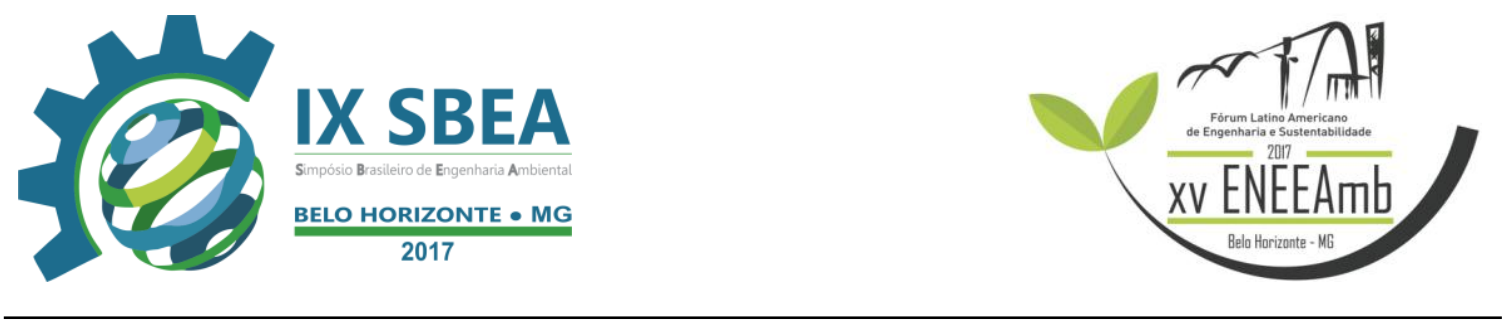

Portanto, considerando o risco em potencial e os efeitos nocivos à saúde e danos a diversos materiais, causados pelo material particulado, este estudo tem como proposta monitorar e quantificar o material particulado coletado na cidade de Goiânia-GO na região central, especificamente na Praça do Trabalhador.

Assim, o presente trabalho objetiva realizar o monitoramento do material particulado na região central de Goiânia - GO, especificamente: monitorar as concentrações de material particulado fino e grosso, MP 2,5 e MP10, respectivamente, em microgramas por metros cúbicos, na Praça do Trabalhador em Goiânia; obter concentrações de material particulado fino e grosso em períodos de estiagem e chuvoso para análise das relações quantitativas.

\section{METODOLOGIA}

O município de Goiânia situa-se na região do Centro Goiano, o ponto de amostragem está localizado na Praça do Trabalhador (região central da capital) e possui uma importância estratégica. As imediações são densamente ocupadas por edifícios públicos (Câmara Municipal de Goiânia, Tribunal de Contas do Município, Cartório, Terminal Rodoviário de Goiânia e hospitais), edifícios privados destinados ao comércio em geral (Estação Goiânia, Araguaia Shopping, hipermercado e hotéis). A Praça do Trabalhador é rodeada por avenidas e ruas de grande fluxo de veículos (Avenida Goiás Norte, Avenida Independência e Rua 44).

A coleta de material particulado foi feita utilizando o amostrador AFG, cujo equipamento coleta material particulado por impactação inercial em duas frações separadamente. Ou seja, através do processo de sucção o ar passa primeiramente pelo filtro grosso depositando material particulado entre 2,5 e 10 micrômetros. Em seguida esse mesmo volume passa pelo filtro fino retendo material particulado abaixo de 2,5 micrômetros.

A fração fina com partículas menores que 2,5 $\mu$ m (fração fina ou inalável) foi coletada por filtros com diâmetro de poro de $0,4 \mu \mathrm{m}$ e a fração grossa (fração grossa ou respirável) com partículas com diâmetros entre $2,5<\mathrm{dp}<10 \mu \mathrm{m}$ foi coletada por filtros possuindo diâmetros de poro de $8 \mu \mathrm{m}$, (MATSUMOTO, 2000). 


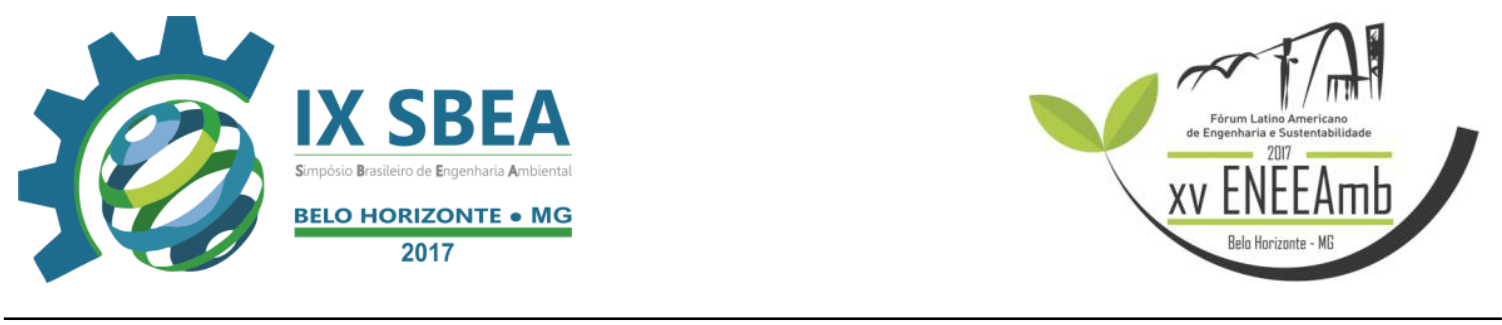

Para a coleta de material particulado foram utilizados filtros de teflon com diâmetros de $47 \mathrm{~mm}$. O uso de filtros de teflon poderá apresentar eficiência na seleção dos diâmetros de corte de até 50,\% (NETTO, 1995; PARKER et al., 1997 apud LOPES, 2003). Os filtros são acoplados ao amostrador AFG e posicionados a aproximadamente 1,5 metros solo que é em média a altura de um brasileiro. $\mathrm{O}$ amostrador foi ligado a uma tubulação de admissão (inlet), na qual é projetado para capturar partículas menores que $10 \mu \mathrm{m}$ (LOPES, 2003). Ambos os equipamento (AFG e Inlet) são ligados a uma bomba de vácuo onde o fluxo de ar foi mantido a $25 \mathrm{~L} \cdot \mathrm{min}^{-1}$ e a um totalizador de volume, sendo que esse volume é em média a quantidade de volume que um pulmão humano realiza em 24 horas.

Antes do período de exposição para amostragem, cada membrana foi cuidadosamente pesada, na balança analítica disponível no laboratório de Engenharia Ambiental do Instituto Federal de Goiás - Campus Goiânia, e as informações sobre a data da coleta, porosidade da membrana (diâmetro: fino; grosso), da massa são registrados antes e depois de 24 horas corridas de amostragem. Assim, através da diferença entre o peso final e o inicial da massa das membranas foi possível obter a massa do material particulado retido em cada filtro, bem como obter o volume de ar amostrado nas 24 horas, conforme Equação 1:

$$
\mathrm{Q}_{\left(\mathrm{m}^{3}\right)}=\mathrm{R}_{\text {final }}-\mathrm{R}_{\text {inicial }}
$$

Sendo,

$\mathrm{Q}\left(\mathrm{m}^{3}\right)=$ Vazão de ar registrada após 24 horas de amostragem, em m³

$\mathrm{R}($ inicial $)=$ Registro inicial, medidor de vazão desligado, $\mathrm{em}^{3}$;

$\mathrm{R}($ final $)=$ Registro final no medidor após amostragem de 24 horas, em $\mathrm{m}^{3}$.

Destarte, estende-se a mesma lógica de cálculo para obtenção da massa retida em cada filtro, conforme Equação 2.

$$
\mathrm{M}_{(\mathrm{g})}=\mathrm{M}_{\text {final }}-\mathrm{M}_{\text {inicial }}
$$




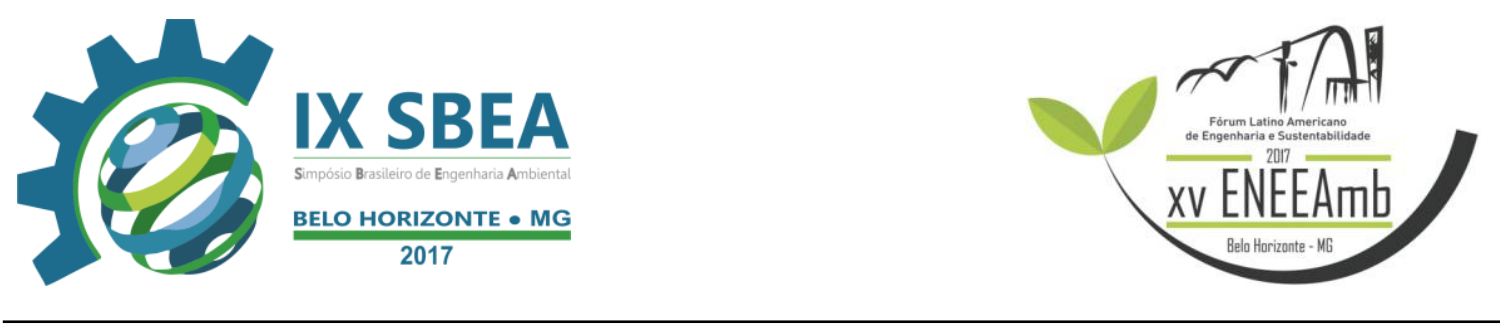

Sendo,

$\mathrm{M}(\mathrm{g})$ = Massa retida em cada filtro após 24 horas de amostragem, em gramas;

$\mathrm{M}($ inicial $)=$ Massa inicial do filtro branco, ausente MP, em gramas;

$\mathrm{M}($ final $)=$ Massa final do filtro após amostragem de 24 horas, em gramas.

Com efeito, cada membrana foi acondicionada em uma placa de Petri e identificada conforme o tipo de material particulado (fino ou grosso), ou seja, de acordo com cada fração retida. Em conformidade com as boas práticas de laboratório todo o manuseio das membranas é feito com uso de jaleco, luvas descartáveis e pinça de plástico.

Dessa forma, o resultado final por medição pode ser apresentado através da relação massa/volume, ou seja, em microgramas por metros cúbicos, conforme Equação 3.

$$
\mathrm{C}_{\mathrm{MP}}=\frac{\mathrm{M}_{(\mathrm{g})}}{\mathrm{Q}_{\left(\mathrm{m}^{3}\right)}} \times 10^{-6} \mu \mathrm{g} / \mathrm{m}^{3}
$$

Sendo,

$\mathrm{CMP}=$ Concentração de material particulado, fino ou grosso, em $\mu \mathrm{g} \cdot \mathrm{m}^{-}{ }^{3}$.

\section{RESULTADOS E DISCUSSÃO}

Considerando o objetivo da proposta do presente estudo, os resultados obtidos fazem referência a concentrações de material particulado fino e grosso, MP2,5 e MP10, respectivamente, retida em filtros de teflon. O período de desenvolvimento das amostragens é classificado sazonalmente como estação chuvosa.

As concentrações de MP fino e grosso $\left(\mu \mathrm{g} . \mathrm{m}^{-3}\right)$ aferidas nas amostradas no período chuvoso, dezembro de 2015, seguem conforme Figura 1. 


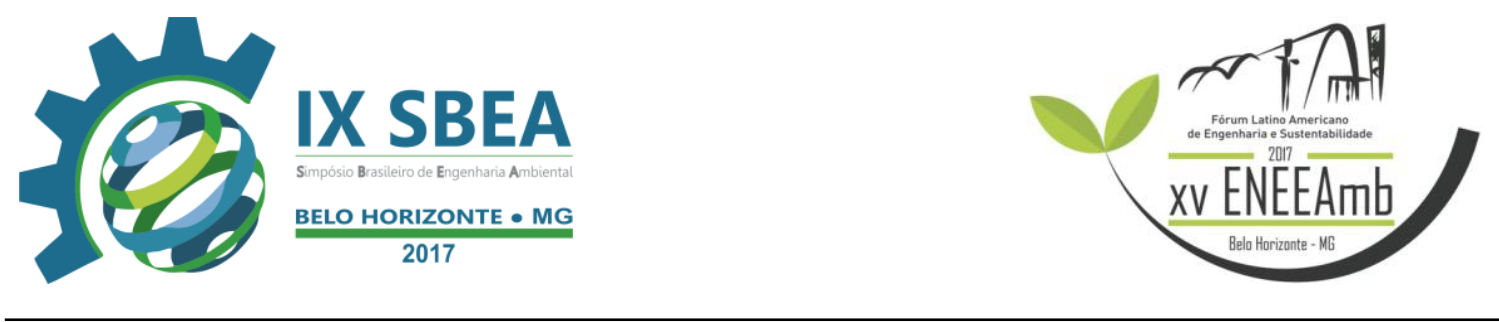

Concentraçao de MP Dezembro 2015 fltro Teflon

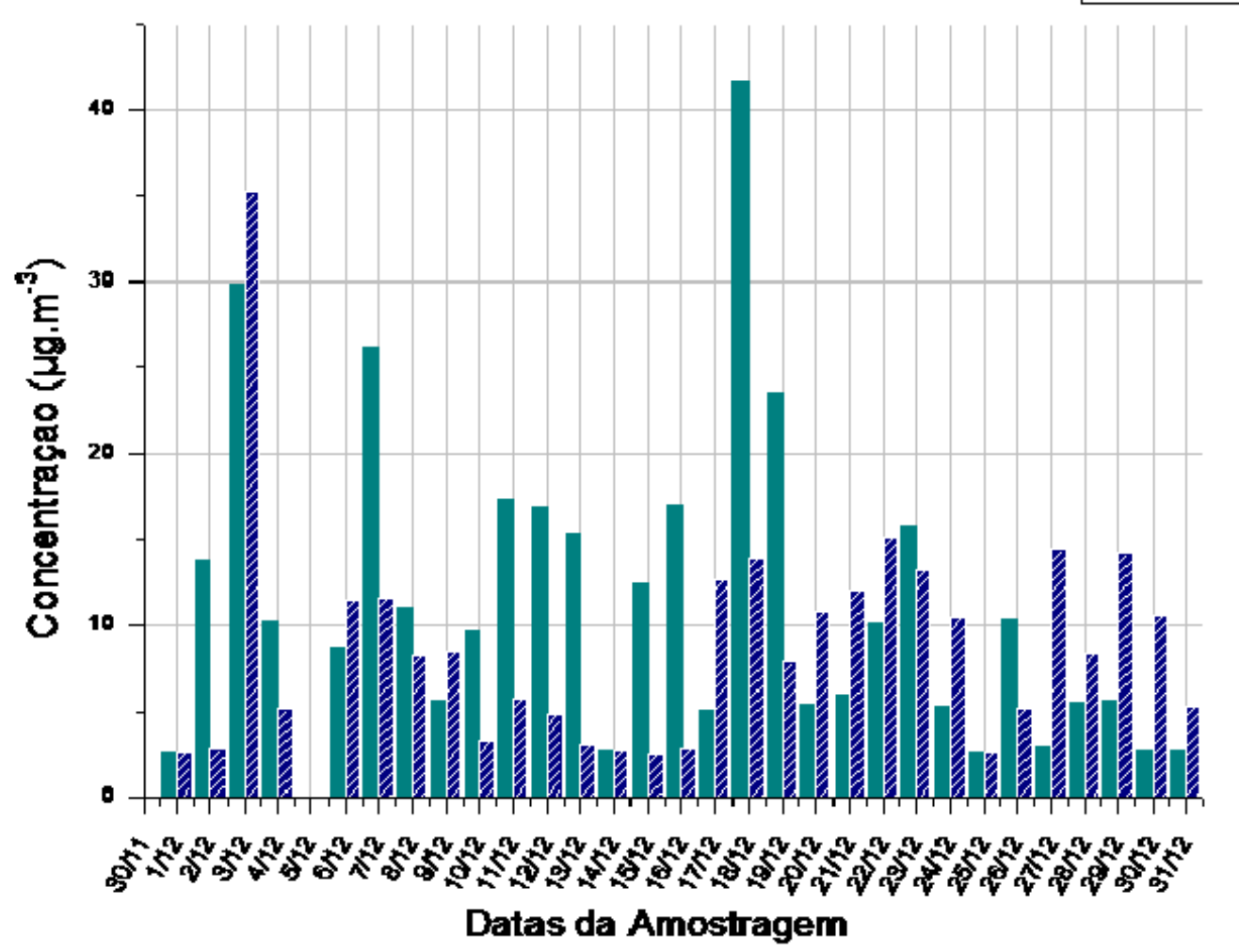

Figura 1 - Concentração de MP em filtro de Teflon 2015 em Goiânia - GO.

Assim, durante o período amostral observou-se a maior presença de material particulado fino. Com destaque para os dias 18/12 que ultrapassou $40 \mu \mathrm{g} . \mathrm{m}^{-}{ }^{3}$ e nos dias 03, 07, e 19/12 quando ocorreram concentrações de MP2,5 respectivamente 29,8, 26,1 e 23,5 $\mu \mathrm{g} \cdot \mathrm{m}^{3}{ }^{3}$. Da mesma forma e não menos importante verificou-se elevada concentração de MP10 no dia 03/12 atingindo 35,2 $\mu \mathrm{g} \cdot \mathrm{m}^{-3}$.

Portanto, esses são valores expressivos para material particulado presente no ar atmosférico tendo em vista os malefícios na saúde humana já constatada por SILVA (2013) e CESAR (2013) dentre outros autores. Sendo assim, Goiânia é merecedora de especial atenção devido à mesma apresentar características em comum com as cidades estudadas por esses autores, pois é uma metrópole em desenvolvimento e associado a isso, segundo a Secretaria de Saúde de Goiás (2016), têm-se altos índices de doenças respiratórias que variam durante o ano.

\section{CONCLUSÕES/RECOMENDAÇÕES}




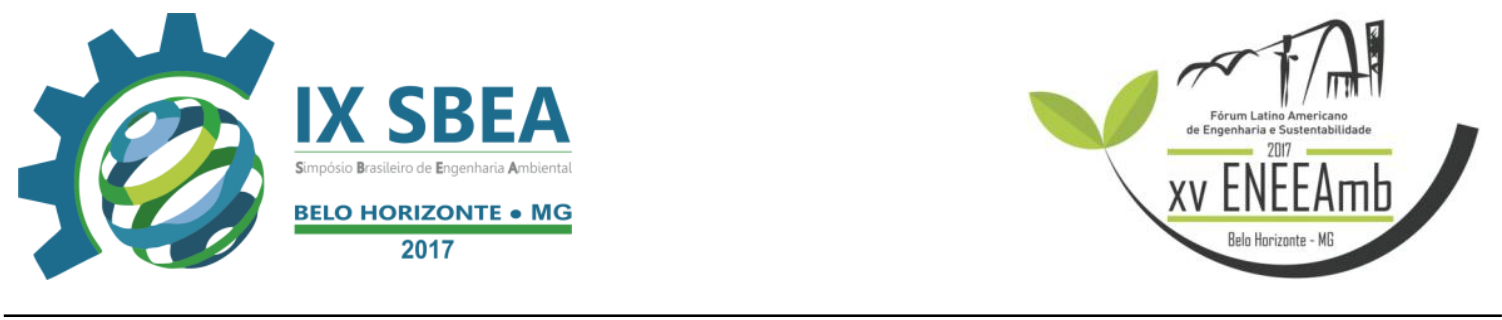

A quantificação do material particulado coletado na região central da cidade de Goiânia-GO no período de 01 a 31 de dezembro de 2015, indicou concentrações críticas principalmente para o particulado fino uma vez que essas partículas tem poder de penetração que podem alcançar profundidades maiores no organismo que o material particulado grosso, já comprovado segundo vários autores, tendo em vista as evidências dos efeitos toxicológicos dessas partículas na saúde humana.

Desse modo, o monitoramento e as análises das concentrações obtidas do material particulado na região central de Goiânia evidencia a necessidade de realizar estudos com períodos prolongados de amostragens para que se tenha um maior banco de dados e assim uma base comparativa mais significativa possibilitando correlações entre saúde humana e meio ambiente, inferindo, desta forma, a necessidade da adoção de parâmetros legais ainda não estabelecidos no Estado de Goiás e Brasil.

\section{REFERÊNCIAS BIBLIOGRÁFICAS}

CALIJURI M. do C.; CUNHA D. G. F. Engenharia ambiental: conceitos, tecnologia e gestão. Rio de Janeiro: Elsevier, 2013. 832 p.

CAStAnHo A.D. de A. A Determinação Quantitativa de Fontes de Material Particulado na Atmosfera da Cidade de São Paulo. São Paulo, 131 p., 1999. Dissertação (Mestrado) - Universidade de São Paulo.

CESAR A. C. G. et al., Associação entre exposição ao material particulado e internações por doenças respiratórias em crianças. Revista Saúde Pública, São Paulo, v. 47, n. 6, p. 1209-1212, 2013.

COLLS, J. Air Pollution. USA: SPON Press Taylor \& Francis Group, 2002.

COMPANHIA AMBIENTAL DO ESTADO DE SÃO PAULO. Material particulado inalável fino (MP2,5) e grosso (MP10) na atmosfera da região metropolitana de São Paulo (2006 - 2008). São Paulo; CETESB, 2008.

COSTA E SILVA, P. H. Caracterização química de material particulado fino e grosso em Goiânia, GO. Goiânia, 49 p., 2015. TCC (Trabalho de Conclusão de Curso) - Instituto Federal de Goiás. 


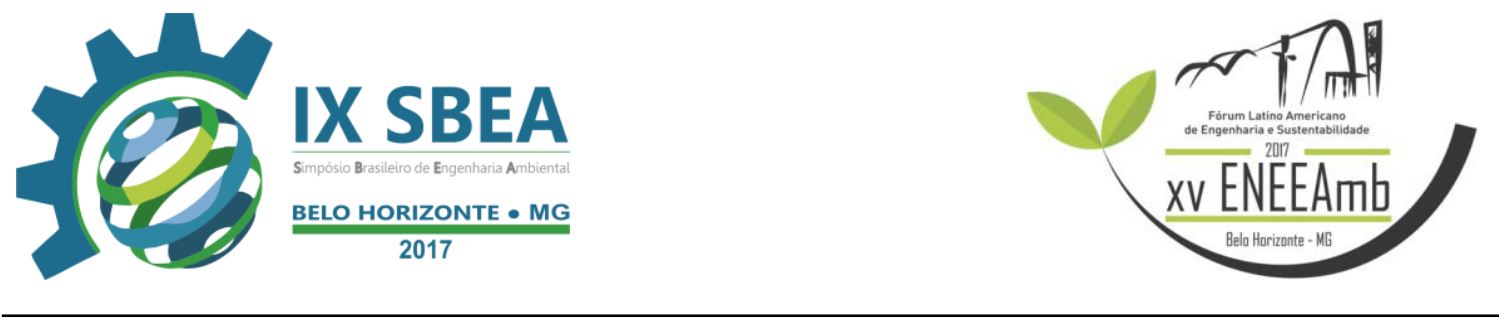

DEPARTAMENTO ESTADUAL DE TRANSITO de Goiás - DENATRAN. Evolução da Frota por Município, 2013. Disponível em: http://www.segplan.go.gov.br. Acesso em 05 jan. 2015.

GODISH, T. Air quality. Boca Raton: CRC Press, LLC, 1997. 480 p.

LOPES F. Caracterização química do material particulado suspenso na atmosfera empregando a fluorescência de raios $\mathrm{X}$ dispersiva em energia (EDXRF). Piracicaba, 106 p., 2003. Dissertação (Mestrado) - Universidade de São Paulo.

MAIS SECO, inverno pode aumentar casos de doenças respiratórias. Disponível em: http://www.saude.go.gov.br/view/4747/mais-seco-inverno-pode-aumentar-casos-dedoencas-respiratorias. Acesso em: 19 ago. 2016.

MATSumoto, E. Estudo da Contaminação Ambiental Atmosférica e de Águas Superficiais, Empregando a Fluorescência de Raios $X$ Dispersiva em Energia (EDXRF) e Reflexão Total (TXRF). Campinas, 150 p., 2000. Tese (Doutorado) Universidade Estadual de Campinas.

NETO, A. S. et al., O processo de transformação da gestão ambiental. In:

Fundamentos da gestão ambiental. Rio de Janeiro: Editora Ciência Moderna Ltda, 2009. P. 23-65.

NETTO, P.E.A. Modelos receptores aplicados à determinação da estrutura de fontes de aerossóis remotos. São Paulo, xxx p., 1995. Tese (Doutorado) Universidade de São Paulo.

PASQUALETTO, A. Ar. Goiânia: UCG/Kelps, 2009. 104 p.

PHILIPPI JÚNIOR, A. Saneamento, saúde e ambiente: fundamentos para um desenvolvimento sustentável. Barueri: Manole, 2005. 842 p.

ROCHA J. C. et al., Introdução à química ambiental. Porto Alegre: Bookman, 2009. $256 \mathrm{p}$.

ROMÃO, R. Relação entre baixo peso ao nascer e a poluição do ar no município de Santo André, SP. São Paulo, 27 p., 2010. Dissertação (Mestrado) - Universidade de São Paulo.

SILVA A. M. C. da et al., Material particulado originário de queimadas e doenças respiratórias. Revista Saúde Pública, São Paulo, v. 47, n. 2, p. 345-52, 2013.

WHO - WORLD HEALTH ORGANIZATION. Air Quality Guidelines for Particulate Matter, Ozone, Nitrogen Dioxide and Sulphur Dioxide. Global update 2005. Summary of Risk Assessment. Geneva, 2006. 